\title{
MICROMACHISMOS O MICROTECNOLOGÍAS DE PODER: LA SUBYUGACIÓN E INFRAVALORACIÓN, QUE MANTIENEN EL SIGNIFICADO POLÍTICO Y SOCIAL DEL "SER MUJER" COMO LA DESIGUAL
}

Almudena García Manso

Doutora em sociologia do departamento de comunicação II e ciências sociais na Universidade Rey Juan Carlos. Membro do grupo de pesquisa Methaodos.org. Atuais linhas de investigação: sociologia do gênero, sociologia do corpo e da saúde, sociologia da sexualidade, imigração e intercâmbio cultural e ainda novas tecnologias e inovação.

Artenira da Silva e Silva

Pós-Doutora em Psicologia e Educação pela Universidade do Porto, Doutora em Saúde Coletiva pela Universidade Federal da Bahia, Mestre em Saúde e Ambiente pela Universidade Federal do Maranhão, Psicóloga formada pela PUC-SP. Docente e pesquisadora do Departamento de Saúde Pública da UFMA (graduação de medicina e Mestrado em Direito e Instituições do Sistema de Justiça). Consultora em proteção integral de crianças/adolescentes e em violência intrafamiliar. Coordenadora de linha de pesquisa no Observatório Ibero Americano de Saúde e Cidadania, Psicóloga clínica e forense. Atuais temas de pesquisa: violência intrafamiliar, proteção integral de crianças e adolescentes, homo/transfobia, terminalidade e norte.

\section{Resumo}

Analisando o significado do patriarcado como sistema social de poder atesta-se que a violência contra as mulheres tem se convertido na raíz cultural das sociedades. A violencia é percebida de várias formas, não apenas física, psicológica, sexual ou patrimonial, mas também como violências invisívies: microviolências ou micromachismos e síntomas da mulher contemporânea ( Bonimo, 2005 e Simón, 2010), que fazem da violência um meio de controle da mulher invisível aos olhos da sociedade. A proposta do estudo é fazer uma reindetificação e uma nova busca de outras formas de violência invisíveis, realizando-se uma incursão qualitativa exploratória do fenêmeno pesquisado a partir de grupos focais ou grupos de discussão. As dinâmicas realizadas evidenciaram outras tipologías de microtecnologias de poder ou micromachismos utilizados a fim de perpetuarem os papéis tradicionais de gênero feminino, com suas consequentes significaçóes político sociais: a 
sujeição e a infravalorização, que mantém o significado político e social de "a mulher" como a desigual.

\section{Palavras-chave}

Micromachismos; Microviolências; Violencia contra a mulher; Patriarcado.

\section{Resumen}

Analizando el significado del patriarcado como sistema social de poder comprobamos cómo la violencia contra las mujeres se ha convertido en la raíz cultural de las sociedades. Violencia percibida de muchas formas, no sólo física, psicológica, sexual, económica sino invisible: microviolencias o micromachismos y síntomas de la mujer contermporánea (Bonimo, 2005 y Simón, 2010) que hacen de la violencia un medio de control invisible a los ojos de la sociedad. Nos propusimos hacer una re identificación y búsqueda de otros tipos de violencia invisible, para ello se realizó una incursión cualitativa exploratoria basada en grupos focales o grupos de discusión. De las dinámicas realizadas se llegaron a identificar otras tipologías de microtecnologías de poder o micromachismos afines o perpetuadotes de los roles tradicionales de género femenino con su consecuente significación política-social: la subyugación e infravaloración, que mantienen el significado político y social del "ser mujer" como la desigual.

\section{Palabras clave}

Micromachismos; Microviolencias; Violencia contra la mujer; Patriarcado.

\section{Introducción: Breves Reflexiones Entorno al Patriarcado y la Violencia}

La violencia ejercida contra la mujer es un tipo de agresión encubierta, la cultura patriarcal ha legitimado la creencia de la posición superior del varón frente a la posición socio-política y cultural de la mujer, una situación que ha empujado a la mujer a una posición de inferioridad de poder.

Una de las definiciones más aceptadas de violencia de género es la propuesta por la ONU que define la violencia de género como "todo acto de violencia sexista que tiene como resultado posible o real un dańo físico, sexual o psíquico, incluídas las amenazas, la coerción o la privación arbitraria de libertad, ya sea que ocurra en la vida pública o en la privada" (ONU, 1994).

Bajo esta definición la violencia contra las mujeres, violencia de género o violencia machista se define como coacción física, psíquica o sexual sobre las mujeres con el objetivo claro de influir en su voluntad y obligar al sujeto a actuar en base a esa imposición. 
La violencia adopta diferentes formas tanto física, como verbal, psíquica, sexual, social, económica, simbólica, informativa, etc., maneras de coacción que se vienen ejerciendo, de manera sutil o explícita a lo largo de la historia.

La historia de la violencia de género ahonda sus raíces en la propia historia del patriarcado. No hay un referente claro de cuando surge el patriarcado como estructura de poder, muchas son las referencias que aproximan su existencia a los pequeños grupos sociales prehistóricos, concretamente en la etapa lítica, (Sanahuya, 2002). Aun así se continua insistiendo que es en los albores de las civilizaciones sedimentarias, socialmente estratificadas que definen el concepto de propiedad privada y familia, sopesando la idea que Engels esbozada en su obra El origen de la familia, la propiedad privada y el Estado (2008) quien indica que " el patriarcado comienza a darse en la época histórica, con el régimen monogámico, como una manera de sometimiento de un sexo (el femenino) al otro (el masculino) (Engles, 2008: 253).

Este concepto, el de patriarcado, ha sido uno de los conceptos recurrentes a la hora de explicar o dar a entender las diferencias en la historia de la sociedad. Es a finales de la década de los años sesenta del siglo XX cuando se desarrolla en el feminismo la búsqueda de teorías que permitiesen un abordaje diferente al análisis sobre la subordinación de las mujeres, intentando explicar la desigualdad existente entre los sexos alejadas de la idea de patriarcado como sistema de poder basado únicamente en la productividad y la familia. Es en este punto en el que cuestionan la idea clásica defendida desde el siglo XVII cristalizada en la idea del "derecho del padre", al referirse al sistema que históricamente deriva de las legislaciones griega y romana, legislaciones y sociedades en las que el padre era el cabeza de familia de una unidad doméstica, el cual ejercía todo el poder legal, económico y social sobre los demás miembros de esa unidad doméstica.

Este uso tradicional hacía que el patriarcado solamente tuviera vigencia desde la antigüedad hasta el siglo XIX con la concesión de los derechos civiles a las mujeres. Un uso que distorsiona la realidad histórica ya que "la dominación patriarcal de los cabezas de familia es anterior a la antigüedad clásica y, por otro lado, en el siglo XIX, la dominación masculina dentro de la familia cambia pero no finaliza” (Lerner, 1990: 340)

Un primer intento de redefinición del patriarcado fue el que Kate Millet en su obra Sexual Politics (1970) da sobre patriarcado considerándolo como una institución política, una red de estructuras sociales cuyo nexo común y articulador no era otro más que el cariz político de las relaciones entre los sexos. En este sentido Millet da un nuevo sentido al concepto rompiendo con la idea clásica y tradicional del cabeza de familia. Para Millet patriarcado se desliga de la idea del derecho connatural que poseen los padres, sino el derecho y poder que poseen los hombres en general, y los maridos en particular, unos derechos destinados a estructurar las relaciones de poder y dominio sobre las mujeres, con un fin que no es otro que el de garantizar a los hombres el ejercicio de control sobre 
las mujeres. Es en este contexto en el que entra en juego su mencionada afirmación de lo personal es político, una afirmación que se convirtió en un eslogan del feminismo proveyendo al movimiento una perspectiva que hasta entonces no habían tenido a considerar "las relaciones entre los sexos debían ser consideradas como una de las dimensiones fundamentales de la sociedad y, en consecuencia, había que incluirlas en la teoría social y la política” (Sanahuya, 2002: 17).

Esta definición de patriarcado, que incluye la apropiación por parte de los hombres de la capacidad sexual y reproductiva de las mujeres, es ampliada por Lerner (1990) vinculando patriarcado con cambios en la organización del parentesco y en las relaciones económicas, a la aparición de burocracias civiles y religiosas, ligadas en periodos de tiempo al desarrollo de los primeros estados y al surgimiento de cosmogonías que incluían una gran cantidad de divinidades masculinas.

Por otro lado Morace (1993) indica que el nacimiento del patriarcado estuvo acompańado de una cadena o serie de coerciones ininterrumpida que implicaban el uso de la fuerza y la presencia de especialistas -ejército, sacerdotes, jueces, etc.,-- para ejercitarla. Morace indica que sí existieron sociedades "matrísticas", anteriores al patriarcado, que fueron erradicadas y subyugadas por la imposición del poder masculino. En este sentido el igualitarismo es sustituido por la competencia, imponiéndose la omnipotencia y omnipresencia de la coerción, la violencia y el control.

Así mismo esta autora que define a las sociedades matrísticas como sociedades asamblearias y de discurso, negociación y paz caen ante la privación de los derechos políticos para gran parte de su población -mujeres, niños, extranjeros, etc.,-, surgiendo cargos políticos que se convierten en hereditarios - por vía masculina- y retribuidos, es en este momento en el que aparece la propiedad privada.

Carol Pateman (1995) señala que el patriarcado como sistema de poder político sigue en plena vigencia aunque su definición continua siendo ambigua y confusa. Pateman ve necesaria la distinción de tres formas de patriarcado con el fin de evitar ambigüedades, formas que aun siendo diferentes no se excluyen entre sí. La primera forma es la del pensamiento patriarcal tradicional el cual asimila todas las relaciones de poder al derecho paterno o regla del padre -mencionada anteriormente por la cual se abre el debate del agotamiento conceptual del patriarcado-, un pensamiento acompańado de toda una mitología sobre cómo surge la propiedad privada a partir del nacimiento de la familia, lo cual deja en vigor la tesis propuesta por Engels. La segunda forma consta de la teoría del patriarcado clásico, la cual sostiene que el poder patriarcal y el poder político no son análogos sino por el contrario idénticos. Los hijos nacen bajo la sujeción de sus padres y por ello bajo la sujeción política. Es en este sentido cuando se considera al derecho político como natural y no convencional, siendo el poder político paternal cuyo origen es el poder del procreador del padre. 
La tercera forma es la del patriarcado moderno, que consiste en la transformación a finales del siglo XVII -el periodo de la acumulación del capital- de la teoría clásica del patriarcado, mediante las aportaciones de los teóricos del contrato social. Es el patriarcado moderno denominado "fraternal y contractual" y especulador de la sociedad civil capitalista.

El concepto de patriarcado tuvo una gran acogida en los Estados Unidos sobre todo durante la década de los setenta, poco después se afianzo en Europa y no fue hasta mediados de la década de los ochenta cuando se extiende el concepto de patriarcado a otros países de Asia, América latina y África, en el caso de los países que estaban en proceso de lucha por su independencia colonial este retraso se pudo deber "al temor que la lucha contra el patriarcado quebrantara la solidaridad de las mujeres de izquierdas con sus hombres en las guerras de liberación contra el colonialismo" (Rivera, 1994: 74-75).

Todos estos estudios sobre patriarcado centraron su atención en exponer cómo el derecho de los hombres estructura las relaciones de poder sobre el cuerpo de las mujeres, dirigiendo su atención a la subordinación de las mujeres y considerando la reproducción y/o la sexualidad femenina como las claves del patriarcado. De ahí la importancia de la sexualidad en los procesos de violencia de género.

El patriarcado desde estos primas consiste en "una toma de poder histórica por parte de los hombres sobre las mujeres, cuyo agente ocasional fue de orden biológico, si bien elevado éste a categoría política y económica. Dicha toma de poder pasa forzosamente por el sometimiento de las mujeres a la maternidad, la represión de la sexualidad femenina y la apropiación de la fuerza de trabajo total del grupo dominado, del cual su primer pero no único producto son los hijos..." (Sau, 1990: 237-238).

La categoría patriarcado se atribuye así misma todo lo negativo de la experiencia pasada y presente de las mujeres, se presenta como "algo a histórico, eterno, invisible e inmutable" (Lerner, 1990:67). Un término que sigue en vigor y vigencia -utilizado para ser criticado- y que hace clara referencia a la sujeción de las mujeres, singularizando la forma de derecho político que detentan los varones.

Una vez perfilado el contexto social en el que los sujetos han vivido, viven y vivirá la humanidad, el patriarcado, no nos cabe duda alguna que ese sistema de poder marca la cosmovisión y las realidades del sujeto que habita en una sociedad, dirigida, creada y marcada por los valores, pautas, moral, conducta, distribución productiva y social, etc por el modelo patriarcal de sociedad y poder.

La socialización en su amplio sentido se lleva a cabo en contextos sociales, no lejos de una colectividad, influida por ésta y por los grupos sociales inmediatos y de referencia para con el sujeto en vías de socialización. En todo esto cabe el patriarcado, como sistema 
lo abraca todo incluyendo la socialización de los individuos, influyendo en las actitudes, conductas, formas de ser y pensar de aquellos que pasan por sus redes.

La memoria colectiva, el consciente e inconsciente colectivo va forjándose a golpe del cincel del sistema social que encabeza el poder, es por ello por lo que esta memoria colectiva posee infinitud de matices discriminatorios contra los "otros", en este caso las "otras" las mujeres. La diferencia en el patrón general del patriarcado y en los patrones generales de la memoria colectiva se va tornando en desigualdad en cuanto que se incluye el factor división de poderes y reparto o división del trabajo sexual, una base fundamental del concepto del patriarcado como bien hemos contemplado anteriormente.

Reflexionar entorno a la violencia de género y el patriarcado puede representarse en una serie de pasos a considerar la construcción de la identidad en cuanto a las esferas de interacción del sujeto con la violencia como problema estructural y no coyuntural. Los diferentes tipos de violencia manifiesta, latente e invisible o invisibilizada. Las esferas sociales de carácter público y privado.

La construcción de la identidad se lleva a cabo de manera par al proceso de socialización, ésta inicia con el nacimiento del sujeto, dura a lo largo de toda la vida y se funda en las relaciones que se establecen entre el individuo y los demás grupos sociales, sean estos primarios o secundarios. Un proyecto de vida en el que cada individuo va discerniendo entre quien es, quien quiere ser y quien es para los demás, una construcción del yo hacia el vosotros y el nosotros que va cambiando según cosmovisiones de los agentes de socialización.

Dependiendo de qué variables sociológicas -incluyendo aquí todas las variables sociales- se den en ese momento en el contexto sociocultural, los grupos se irán constituyendo en agentes socializadores para cada rol social. Edad, estatus económico, género y etnia por ejemplo, como variables a considerar marcan el recorrido en la conformación y construcción identitaria, la socialización no es inocua a las variables sociales.

En el momento que los sujetos son adscritos a un género determinado, regido por el patrón heteronormativo del patriarcado que no es otro que el sistema sexo/género binario -masculino/femenino-, el sujeto ya con su género -por imposición social- recibe un bagaje cultural distinto en todas y cada una de las esferas o espacios sociales en los que transite desde su nacimiento y a lo largo de todo su proceso de socialización y resocialización. En todas y cada una de esas esferas sociales se haya codificada las normas del patriarcado, los valores y la cosmovisión que hace que la diferencia termine siendo desigualdad, que se perciba a la mujer como otra, un sujeto infravalorado e infravalorable, un objeto más que un sujeto, ofreciendo un desigual reparto de poderes y espacios sociales. El privado para a ser espacio de la mujer, el público es el espacio del hombre, recayendo de esta forma todo el poder fáctico y real sobre él (Pérez Fernández, 2009). 
En estos procesos de socialización y conformación de la identidad, las interrelaciones que se efectúan entre el sujeto y la sociedad están plagadas de ańadidos, sujeciones e intenciones que dirigen o re dirige la vida de los sujetos al son de las necesidades, intereses o deseos de quien o quienes detentan el poder. El sistema, en este caso ya definido rotundamente como patriarcal, marca unas tecnologías de poder que como bien define Michel Foucualt (2005a;2005b y 2005c; 2010) empujan al sujeto social a su sujeción por la biopolítica, tecnologías de poder que se enmarcan perfectamente en los intereses de la dominación masculina, una biopolítica (Foucualt, op cit), tecnopolítica (Winner, 1987), infopolítica (Lash, 2005) y psicopolítica (Byung-Chul, 2014) que siguen las pautas de la otredad femenina, un proceso de othering (Young, 2012) que se entremezcla con los logros civiles, legales, políticos y económicos conseguidos.

\section{Cuando lo Normal se Convierte en una Trampa: Microtecnologías de Po- der del Género}

Si bien es cierto las grandes violencias son vistas e identificadas no sólo por su condición dolosa sino por su existencia en el marco legislativo, en ocasiones las "cosas" pasan a existir cuando las enmarcamos dentro de una tecnología de poder (Foucault, op. cit), en el caso de la violencia contra las mujeres ésta comienza a ser visible y a "existir" como un problema social -que lo ha sido desde siempre- en el preciso instante en el que las leyes y las estructuras de poder la van incorporando, enunciando y legislando el problema identificado como tal.

Además de las violencias visibles, la violencia física y psicológica que queda situada en el marco de la ley y de lo punible, existen muchas otras violencias contra la mujer que lastran de igual manera la capacidad de poder y el avance en materia de igualdad de oportunidades, derechos y reconocimiento público, social, político y cultural. Unas violencias invisibles pero dañinas que son la antesala en ocasiones de la violencia física así como son el lastre del que todas las mujeres tienen que tirar para poder conseguir unas oportunidades y unas condiciones de paridad lógicas e idénticas a las de sus compañeros varones.

Estas violencias designadas por muchas y muchos como violencias blandas, violencias de corto alcance o micromachismos forman parte de una trampa mayor, la trampa de lo cotidiano, del día a día, de la gota que hace mella por su insistencia en la piedra. Es la insistencia, la replicación o performatividad, la normalidad o cotidianeidad lo que hace que estas violencias no sean tan visibles, además de que su existencia reside en multitud de ocasiones en las esferas de lo doméstico, privado y emotivo sentimental de las relaciones inter personales y sentimentales (Llorente, 2014).

Aunque la mujer en algunos lugares del mundo, concretamente en el caso que nos ocupa es el de España, ha logrado alcanzar cotas de poder público sigue lastrada no sólo 
por esas microviolencias o micromachismos sino por fallos estructurales y sistémicos, no debemos olvidar que la inquina hacia la mujer, las estructuras de poder y de intereses del patriarcado, se encaminan a arrinconar a la mujer a una posición de clara inmanencia, dejando que no logre sus metas profesionales de forma completa, haciendo que siempre salga a la luz sus "cualidades naturales" de mujer, madre, cuidadora y emocionalmente activa (Gallego, 2010), lo cual la re-sitúa de continuo en esa posición de lo emocional -por lo tanto lejano a lo racional-, de lo doméstico y de las esferas de cuidado y subordinación. Aun así son muchas metas las alcanzadas, su incorporación en el mercado laboral -incorporación a medias y criticable-, su capacidad de poseer una independencia política, ideológica, económica y educativa, etc., hacen que la mujer española del siglo XXI se aleje cada vez más de la mujer que fue sobre todo durante el Franquismo, ese "ángel del hogar" (Cayuela, 2014).

"Los micromachismos comprenden un amplio abanico de maniobras interpersonales que impregnan los comportamientos masculinos en lo cotidiano (...) Los micromachismos son microabusos y microviolencias que procuran que el varón mantenga su propia posición de género (...) Están en la base y son el caldo de cultivo de las demás formas de violencia" (Bonino, 1995: 4). El término micromachismo o microviolencias de género nace con el fin de identificar aquellas conductas cotidianas, sutiles y comunes que forman parte de las estrategias de control patriarcal.

Materializados en actitudes, conductas y comportamientos los micromachismos no son más que estrategias de control dosificadas en pequeñas acciones o acciones propias de lo cotidiano y el día a día, es por ello por lo que son tecnologías de control menos visibles y por ello más dañinas.

Estas pequeñas formas de manifestar el machismo y la indiferencia o infravaloración a las mujeres han ido haciendo mella en cómo la cultura y la sociedad ha ido conformando los espacios de poder de género, dejando claro que las diferencias y desigualdades en materia de género siguen vigentes y mantienen intactos los tradicionales espacios de poder: el poder público/masculino y la esfera privada y doméstica/femenina.

Los micromachismos suelen permanecer invisibles o por intereses invisibilizados, camuflados, escondidos, interiorizados y normalizados puesto que se dan en las esferas sociales de lo más íntimo y privado, en lo interpersonal e interrelacional, formando parte de los circuitos cerrados de lo usual dentro de una comunidad en concreto (Martínez y Bonilla, 2000). Micromachismos en su mayoría están legitimados por la sociedad y la cultura que los rodea, son actitudes de tolerancia permitida, son prácticas de dominación masculina que se dan en la vida cotidiana, como por ejemplo interrumpir cuando una mujer habla, hacer chantaje emocional, controlar los contactos y horarios de las mujeres, criticar su ropa o el maquillaje, abusar de la condición de cuidadora, decir un piropo o miradas lascivas, ocupar más espacio en el transporte público impidiendo que la mujer pueda sentarse cómodamente. 
Como podemos contemplar los micromachismos son comportamientos abusivos, micro comportamientos que se tornan en efectivos puesto que el orden social preponderante, el sistema cultural del patriarcado, los ratifica y valida. Se ejercen de manera reiterada hasta que anulan a las mujeres o merman su autonomía. La forma en la que se ejercen y lo sutil de su existencia, así como su reiteración, hacen que en la mayor parte de las ocasiones éstos pasen desapercibido e inadvertidos para la sociedad y para sus víctimas.

Estos comportamientos abusivos se diferencian en cuatro tipologías descritas por Bonino $(1995,2005)$ y que representamos en la siguiente tabla.

\begin{tabular}{|c|c|c|}
\hline Tipo & Explicación & Actitudes, comportamientos y actos. \\
\hline Utilitario & $\begin{array}{l}\text { Éstos se corresponden } \\
\text { con estrategias } \\
\text { de imposición } \\
\text { de sobrecarga } \\
\text { por evitación de } \\
\text { responsabilidades, ya } \\
\text { sena éstas domésticas, } \\
\text { familiares, laborales, } \\
\text { intelectuales o } \\
\text { nutricias. }\end{array}$ & $\begin{array}{l}\text { No responsabilizarse sobre lo doméstico, } \\
\text { no implicarse, seudo implicación o } \\
\text { implicación ventajosa, aprovechamiento } \\
\text { abusivo y naturalización de las capacidades } \\
\text { "femeninas de servicio" y de cuidado, } \\
\text { delegación de las tareas de cuidado en } \\
\text { la mujer, negación de } 1 \text { reciprocidad, } \\
\text { naturalización y aprovechamiento de la } \\
\text { ayuda, amiguismo paternal. }\end{array}$ \\
\hline Encubiertos & $\begin{array}{c}\text { El varón oculta } \\
\text { su objetivo de } \\
\text { dominio, maniobras } \\
\text { extremadamente } \\
\text { sutiles e imperceptibles } \\
\text { en la mayoría de las } \\
\text { ocasiones que suponen } \\
\text { una doble trampa, } \\
\text { la cultural y la de la } \\
\text { normatividad social, } \\
\text { por su invisibilidad } \\
\text { e inadvertividad } \\
\text { son más efectivas } \\
\text { que las maniobras } \\
\text { llevadas a cabo en } \\
\text { los micromachismos } \\
\text { directos. }\end{array}$ & $\begin{array}{l}\text { Falta intimidad, silencio, aislamiento } \\
\text { y malhumor manipulado, puesta de } \\
\text { límites, avaricia de reconocimiento } \\
\text { y disponibilidad, inclusión invasiva } \\
\text { de terceros y colisión con terceros, } \\
\text { seudointimidad, seudocomunicación, } \\
\text { comunicación defensiva-ofensiva,engaños } \\
\text { y mentiras, manipulación emocional, } \\
\text { enfurrunamiento, dobles mensajes } \\
\text { afectivo/agresivos, hacerse el inocente, } \\
\text { abuso de confianza, seudonegociación } \\
\text { y desautorización, descalificación y } \\
\text { desvalorización, negación de lo positivo, } \\
\text { autoindulgencia y autojustificación, } \\
\text { minusvaloración de los propios errores, } \\
\text { echar las culpas a otra persona o a la } \\
\text { situación, hacerse el bueno o el tonto, } \\
\text { olvidos selectivos }\end{array}$ \\
\hline
\end{tabular}




\begin{tabular}{|c|c|c|}
\hline Tipo & Explicación & Actitudes, comportamientos y actos. \\
\hline De crisis & $\begin{array}{c}\text { Suelen utilizarse } \\
\text { para restablecer el } \\
\text { reparto previo de } \\
\text { poder y mantener } \\
\text { la distribución } \\
\text { desigual de poder } \\
\text { en el momento en } \\
\text { el que el poder de la } \\
\text { mujer aumenta, ya se } \\
\text { deba este aumento a } \\
\text { cambios exógenos a su } \\
\text { postura personal como } \\
\text { puede ser un cambio } \\
\text { en su vida o por la } \\
\text { pérdida de poder por } \\
\text { parte del varón debido } \\
\text { a incapacidades físicas, } \\
\text { económicas, sociales y } \\
\text { /o personales. }\end{array}$ & $\begin{array}{l}\text { Hipercontrol, seudoapoyo, resistencia } \\
\text { pasiva y distanciamiento, regir la crítica y } \\
\text { la negociación, prometer y hacer méritos, } \\
\text { hacerse la víctima, dar lástima. }\end{array}$ \\
\hline Coercitivos & $\begin{array}{c}\text { Actos o } \\
\text { comportamientos } \\
\text { donde el varón usa } \\
\text { la fuerza moral, } \\
\text { psíquica, económica o } \\
\text { personal para intentar } \\
\text { doblegar a las mujeres } \\
\text { y convencerlas de } \\
\text { que ellas no tienen la } \\
\text { razón, provocando en } \\
\text { ellas un sentimiento } \\
\text { de derrota posterior } \\
\text { al comprobar que la } \\
\text { pérdida, ineficacia o } \\
\text { falta de capacidad y/o } \\
\text { peso político suficiente } \\
\text { como para poder } \\
\text { defender sus propias } \\
\text { decisiones o razones. }\end{array}$ & $\begin{array}{l}\text { Coacciones a la comunicación, control del } \\
\text { dinero, uso expansivo o abusivo del espacio } \\
\text { y el tiempo APRA sí, inexistencia abusiva, } \\
\text { imposición de intimidad, apelación a la } \\
\text { superioridad de la lógica varonil, toma o } \\
\text { abandono repentino del mando. }\end{array}$ \\
\hline
\end{tabular}

Tabla 1, creación propia a partir de Bonino 1995, 2005. 
Pero además de la clasificación y descripción hecha de las herencias del patriarcado, los micromachismos, debemos hacer mención a otras designaciones de interés e importancia a la hora de comprender la violencia contra la mujer desde una perspectiva micro social, en este caso hablaremos del sexismo benevolente.

Por sexismo benevolente se entiende el pensamiento que concibe y considera a las mujeres como sujetos complementarios al varón, naturalizando la diferenciación jerarquizada entre los sexos y justificando el mantenimiento de los roles y discriminación de género. Es un tipo de sexismo al igual que los micromachismos muy perjudicial en este caso no niega a la mujer el acceso a las esferas de poder públicas -económica, educativa, laboral, sanitaria, económica, etc.,- pero por el contrario hace que la mujer tenga que ser ante todo mujer, en el marco del significado cultural que ello conlleva sería que la mujer ha de actuar de manera subordinada y someterse al cumplimiento de los estereotipos de género tradicionales, es decir: ser madre, esposa, cuidadora y objeto de deseo -amante-. Este tipo de sexismo benevolente hace que las mujeres adquieran un unos síndromes, sociales, psicológicos y culturales, a considerar (Simón, 2003:100):

Síndrome de cenicienta, este síndrome consiste en la auto percepción de mujer como torpe, falta de habilidades y que precisa continuamente de dependencia masculina, en este sentido las mujeres que se encuentran bajo este síndrome serían mujeres candidatas a padecer acoso sexual o a ser víctimas claras de violencia de género, así como a ser meros objetos decorativos las común mente denominadas - peyorativamente- mujeres florero o mujeres cuota, mujeres que ornamentan o rellenan candidaturas o que sirven para mostrar una imagen políticamente correcta de instituciones, empresas o asociaciones (Simón, 2003:101). El síndrome de la becaria desclasada, muy propio de mujeres que se camuflan como varones hasta tal punto que rechazan cualquier manifestación femenina por la carga simbólica de inferioridad y negatividad que ello conlleva. Este síntoma suele estar representado por mujeres que llegan a cuotas de poder imitando las estrategias masculinas y asimilando cierto autoritarismo, competitividad negativa y machismo. Por último Simón hace mención del síndrome de la abeja reina, un síndrome que es propio de mujeres que adquirieron posiciones de poder o de reconocimiento importantes y que creen que el esfuerzo y el mérito permite a las mujeres llegar allá donde quieran llegar, tal y como a ellas les ha sucedido. Por lo general este tipo de personas suelen rechazar cualquier medida anti sexista o impulsadota de la igualdad de oportunidades entre hombres y mujeres.

Así como existen otros tipos de machismos "de baja intensidad" o micromachismos que no están especificados pero que sí los podemos detectar por su daño y por lo deducido de la incursión cualitativa que se hizo a este respecto. 


\section{Identificación de Otros Micro Machismo no Representados por Teorías Expuestas}

Para poder realizar esta identificación se realizaron dos aproximaciones o incursiones utilizamos una incursión y/o exploración metodológica de tipo cualitativo basado en dos grupos de discusión realizados tras un taller sobre micromachismos, los participantes del taller y de los grupos de discusión eran alumnos y alumnas universitario de edades comprendidas entre los 20 y 24 ańos, el taller se impartió a todo el grupo (23 hombre y mujeres) y se dividió en dos grupos de discusión o grupos focales de la siguiente forma: grupo número uno compuesto por 12 personas (5 varones y 6 mujeres) y el grupo dos compuesto por 11 personas (4 varones y 6 mujeres).

Tras el análisis de las teorías expuestas en este trabajo y la identificación de actitudes y comportamientos que están englobados en las cuatro categorías de micromachismos expuestas por Bonino $(1995,2005)$ y los síntomas descritos por Simón (2003) se procedió a identificar otros tipos de micromachismos que se escapaban a los expuestos en el taller, en este sentido se pudo describir en un primer momento los micromachismos derivados del uso del lenguaje, insultos y palabras mal sonantes que hacen referencia a la mujer o a lo femenino, infravalorizándola, peyorizándola y minusvalorándola. La ausencia de un lenguaje inclusivo y lo engorroso que supone utilizar un uso no sexista y discriminatorio o peyorativo del lenguaje.

Muchas veces usamos el lenguaje no sexista, el inclusivo cuando hablamos de cara a un público numeroso, por ejemplo en las asambleas de alumnos y alumnas, y creo que es necesario, pero la gente se cansa y se pierde con tanto nosotros y nosotras, ellos y ellas, etc., pero el lenguaje inclusivo es necesario, no usarlo es un micromachismo (Varón de 22 años).

Siempre con el cońo en la boca, que si esto es un cońazo, que si eres un hijo de mala madre, que si la madre que te parió, que si mala perra...etc., el español está lleno de palabras mal sonantes en femenino, hasta para insultar a un hombre se usan términos en femenino, eso es machismo encubierto (Mujer de 21 ańos).

El lenguaje es fundamental para que la gente no sea machista y en España hablamos muy mal, somos machistas en el lenguaje (Mujer 24 años).

Otros micromachismos que se dedujo de los grupos focales giraba entorno a los piropos y el humor, en ambos grupos lo designaban como micromachismos culturales, otros los designaban, haciendo clara referencia a los piropos y cortesías varias, micromachismos de cortesía o "caballerosidad", groseros y soeces, actos intimidatorios sexualmente hablando para las mujeres. En este sentido comentaban cómo los chistes y el humor es tendente a ridiculizar a lo femenino y ha ridiculizar al hombre afeminado, así como en el caso de los micromachismos de caballerosidad o cortesía grosera casi la inmensa mayoría 
de los y las participantes en los grupos de discusión hacían mención a una violencia sexual indirecta en los mismos, siendo éstos los más desagradables y deplorables, considerados por los miembros de los grupos como violencia sexista y sexual.

Cuando estoy en la puerta de la discoteca y veo que a mis amigas las dejan entrar gratis siento pena, muchas veces les digo que eso es machismo y que las consideran trozos de carne para atraer a clientes chicos (Varón, 23 años).

Yo no voy a discotecas donde me tratan como un objeto, si quiero ir me pago mi entrada, lo otro es violencia sexual, te consideran un objeto sexual, un atractivo para los demás (Mujer, 20 años).

Es asqueroso cuando alguien te piropea o te dice una grosería, no hace nada de gracia, te sientes desnudada, yo me siento mal, es una agresión en toda regla (Mujer, 23 años).

Es asqueroso ver cómo en el vídeo en el que una mujer pasea por las calles de Nueva York durante un día y los hombres le sueltan groserías y la increpan cuando ella no hace otra cosa mas que andar por la calle, sin meterse con nadie y sin hacer nada más que andar, ahora va resultar que andar es una provocación (Mujer de 25 años).

Los hombres creen desde pequeños que decir piropos es algo que agrada a las mujeres, creo que lo toman como una forma de agredir y demostrar su masculinidad haciéndolo pasar mal a las mujeres (Varón, 23 años).

Otro tipo de micromachismos que se detectaron en los grupos de discusión son los mediáticos y publicitarios, en este sentido hablaron de lo perjudicial que es el papel de los medios de comunicación en este sentido, la difusión de programas que hacen apología de los roles de género tradicionales, que siguen reivindicando la función clásica de la mujer como cuidadora, madre, esposa y/o amante, manteniendo la idea de la mujer como un objeto y no como un sujeto, una persona en continua minoría de edad o en perpetua inmanencia e inferioridad para con los varones. Esta imagen infravalorada, victimista y en ocasiones hiper sexuada o extremadamente sexual de la mujer no hace nada por generar dinámicas que hagan y posibiliten la consecución de la igualdad de oportunidades y la positivación en poder y valorización de la mujer.

En algunos canales de televisión lo único que te muestran es la imagen de mujer florero o mujer bella, maziza pero tonta (Varón, 21 años)

La publicidad está plagada de mujeres como objetos: o son madres, o son esposas o son bellas pero tontas (Mujer, 20 años).

Muchas revistas femeninas, como por ejemplo la Cosmo, siguen perpetuando la imagen tradicional, pero a la vez liberada sexualmente, de la mujer, ella siempre tiene que estar perfecta y apetecible para el hombre (Mujer, 23 años). 
A esto hay que sumar otro micromachismo que deriva de la supervaloración de lo romántico y lo emocional irracional del amor como última expresión de las relaciones interpersonales, la llamada por los grupos de discusión violencia romántica.

Te venden que ser romántico es querer a la persona, pero eso es un mito: ni regalar rosas significa que te aman ni tener celos significa que te quieren, es todo lo contrario, te compran y te manipulan (Mujer, 24 años).

El príncipe azul, la mujer de tu vida, la felicidad de estar juntos, la vida en rosa, todo eso para dominar tu vida (Varón, 23 ańos).

Os cuentan el cuento de lo romántico para dominaros, y lo peor es que la gente se lo cree, es así desde hace tanto tiempo...desde casi Adán y Eva (risas) (Varón, 20 años).

Ser romántico es dominar a tu chica (Varón, 24 años).

Sin duda la experiencia del otro nos muestra cómo hay multitud de machismos invisibles aún por identificar y como no por visiblizar.

\section{Conclusiones}

Muchas de las consideraciones teóricas sobre las microtecnologías de poder que hemos podido recopilar, en primer lugar a través del marco teórico y del recorrido por el patriarcado y su nacimiento, así como por la experiencia investigadora y profesional de especialistas en violencia de género (Bonino, 2005 y Simón, 2010, Osborne, 2010), han dado su fruto empírico y reflexivo con el fin de cumplimentar las tipologías sobre micromachismos y microviolencias, algunas obviadas otras inadvertidas por su naturalización, en ese sentido de la incursión exploratoria realizada mediante los grupos de discusión pudimos diferencias otras clasificaciones anteriormente no indicadas a señalar: micromachismos lingüísticos, que si bien es cierto este tipo de violencias se vienen estudiando desde el lenguaje, la etno lingüística, la semántica, la semiología y la literatura, etc., disciplinas todas ellas que pretenden hacer un llamamiento por el tratamiento no sexista del lenguaje (Calero, 1999; Gorddard y Patterson, 2005; García Messeguer, 1994; Furtado, 2013) el lenguaje sigue marcando realidades, creándolas y siendo una de las tecnologías de poder, por su capacidad enunciativa y constructora de la realidad, así como por su capacidad de otorgar o no visibilidad o poder a las personas, hechos o cosas. El lenguaje forma parte de las raíces mismas de una cultura y su sociedad, éste marcará y creará las realidades que enuncia, haciendo que éstas sean tal y como son dichas: si el insulto es femenino lo que se peyoriza, infravalora y minusvalora es lo femenino, siendo esto un motivo fundamental para decir que el uso del lenguaje de manera sinuosa y sesgad es pura micro violencia. No podemos olvidar que el castellano, desde tiempos de su conformación, ha estado instalado en una misoginia simbólica que ha construido una forma de pensamiento hasta 
hoy inalterada, la mayoría de los insultos que se usan son de carácter femenino, así como aquellos términos que pretenden negativizar algo son alusivos a lo femenino, así "cońazo" o "cońo" o "portera" se usan en negativo o para infravalorar un hecho, una acción o a una persona (Martínez García, 2008).

Otro de los micromachismos es el del humor, viendo cómo el humor en nuestra cultura es tremendamente misógino y homófobo, cebándose en las alteridades y otredades sociales, los homosexuales y las mujeres -los otros sujetos sexuales no hetero masculinos-. Respecto al humor indicar que tanto los participantes en los grupos de discusión como algunos y algunas expertos y expertas en materia de género tienden a considerar que la ridiculización pública, colectiva y desde un artefacto cultural, como es la narrativa humorística, tiende a tener un efecto doblemente negativo, por un lado consigue su objetivo de deslegitimar y humillar al otro -en este caso que nos ocupa a la otra- y por otro lado genera una narrativa cultural que se tiende a perpetuar y repetir, usando el humos como excusa.

E siguiente machismo es el identificado y denominado como micromachismos de cortesía o "caballerosidad", éstos micromachismos se tienden a fundir con la idea de violencia sexual simbólica, es en este tipo de micromachismos cuando la mujer se siente mas coartada públicamente, más violentada y asumen de forma más directa que lo que están sufriendo no es más que una violación de su intimidad y la recepción de algo que ellas no han pedido y que se hace sin su consentimiento, una perdida completa de su autonomía y un sentimiento de asco y a veces vergüenza que genera en ellas infravaloración. El piropo lejos de ser eso que llaman caballerosidad, que no es otra cosa que machismo adornado, es una pérdida de control de sí mismas, en muchos casos una violación de su intimidad y una agresión sexual -sobre todo por el contenido soez y grosero- simbólica, cultural cercana a lo físico.

El siguiente micromachismo es el de la publicidad enmarcado en los grupos de discusión y cristalizado en los programas o contenidos publicitarios, así como series de televisión y películas que tienden a perpetuar los estereotipos de género femeninos tradicionales, continuando con la idea de la mujer subordinada y objeto sexual del varón. En ocasiones hacen mención de cómo el sexo o la libertad sexual que muchos de esos medios quieren hacer creer encubren actitudes machistas y abusivas contra las mujeres, coartando su libertad individual y cosificándolas u objetivandolas -es decir convirtiéndolas en cosas y/u objetos-.

Para finalizar el último micromachismo identificado por los grupos de discusión fué el micromachismo de tipo romántico, el vender lo romántico y el amor romántico como medio, fin y objetivo último de la vida de la mujer, un romanticismo que no es más que una traducción de la puesta en escena de la manipulación emocional de roles tradicionales 
de género, un relato social que narra la vida al estilo de un cuento de hadas donde ella ha de ser la princesa de tus sueños y él el príncipe azul, dulce y amorosa y él fuerte y protector (Walter, 2010). Este micromachismo también se identifica con los nuevos estilos de vida de la sociedad de consumo, la mercantiliación de la vida íntima, el consumir emociones y el vivir sentimientos consumibles pero encaminados a una dualidad de género en la que las mujeres han de mantener el papel tradicional de subordinación a los deseos del varón (Russell Hochschild, 2008)

Lo que sí tenemos claro es que mientras estos micromachismos no se visibilicen y traten de eliminar de las raíces culturales y en el día a día social la violencia, sea esta visible o invisible seguirá inalterada. Posición que merma de manera directa las oportunidades de paridad, igualdad y mejora de las condiciones de las mujeres. La violencia es sistémica, estructura y endémica, deviene de unos procesos víricos por contaminación socializadora que hacen que la mitad de la humanidad viva en situaciones de clara desventada y falta de derechos. Educar es una de las armas, luchar contra la cultura a veces es como darse golpes contra una pared mientras no se sensibilice a los miembros de esa cultura, hasta que no se les hace ver que el daño de lo que ellos y ellas consideran normal es inmenso, tanto que afecta a todos y todas los miembros de la comunidad, una sociedad desigual es una sociedad sin capacidad de desarrollar de manera correcta, positiva y ética.

Como pequeño ejemplo de herramienta socializadora y sensibilizadora desde las nuevas tecnologías, unos micro espacios del ciberfeminismo o ampliaciones del mismo, podemos referir a aplicaciones para móvil que pretenden sensibilizar en materia de micromachismos y coeducar en la igualdad tal y como la app que está a modo de prueba en la web http://enredatesinmachismo.com/app-para-smartphones/ y que tienen como misión hacer reflexionar al respecto de aquellas actitudes, comportamiento o actos micromachistas. No podemos olvidar la lucha feminista que desde la plataforma Hollaback (http://www.ihollaback.org/), red social que opera en 50 ciudades de 17 países, y que ha lanzado diversas campañas de concienciación para hacer ver cómo las mujeres sufren acoso callejero cuando caminan por las calles de sus ciudades, se esta llevando a cabo, sus videos que demuestran ese acoso y los piropos como arma sexista son muestra de los micromachismos que se han mencionado en esta reflexión entorno a las microtecnologías de poder, esos micro machismos que tienen como fin sujetar al sujeto viviente, en este caso a la mujer, orientando su posición social a la de subordinación e infravaloración, manteniendo con ello los roles tradicionales de género intactos.

\section{Referencias}

BARRY, H; BACON, M.K, CHILD, I.L. Una revisión transcultural de algunas diferencias de sexo en la socialización"en VELASCO, H. (coord.). Lecturas de antropología social y cultural. Madrid, UNED. 1995. 
BONINO, L. Desvelando los micromachismos en la vida conyugal. En CORSI, J. (ed). Violencia masculina en pareja, Una aproximación al diagnóstico y a los modelos de intervención. (pp. 191-208). Buenos Aires, Paidós. 1995.

BONINO, L. La violencia invisible en la pareja. En Primeras Jornadas de género en la sociedad actual. (pp.25-45). Valencia, Generalitat Valenciana. 1996.

BONINO, L. "Las microviolencias y sus efectos: claves para su detección", en RUIZ-

JARABO, C; BLANCO, P (Coords)., La violencia contra las mujeres: prevención y detección. Madrid, Díaz de Santos. 2005.

BYUNG-CHUL, H. Psicopolítica. Barcelona, Herder. 2014.

CALERO, M.A. Sexismo lingüístico. Análisis y propuestas ante la discriminación sexual en el lenguaje. Madrid, Narcea. 1999.

CARRIÓN, F. Violencia y medios de comunicación: populismo mediático, en Revista Latinoamericana de Seguridad Ciudadana. N5, pp. 7-10. 2008.

ENGELS, F. El origen de la familia, la propiedad privada y el estado. Madrid, Alianza Editorial. 2008.

FERRER PÉREZ, V; BOSCH FIOL, E. Introduciendo la perspectiva de género en la investigación sobre violencia de género, en Anales de psicología. Vol 21, n ${ }^{\circ}$, pp. 1-10. 2005.

FOUCAULT, M. Historia de la sexualidad I: La voluntad del saber. Madrid, Siglo XXI. 2005 a.

. Historia de la sexualidad II: El uso de los placeres. Madrid, siglo XXI. 2005 b.

. Historia de la sexualidad III: El cuidado de sí. Madrid, Siglo XXI. 2005 c.

. Vigilar y Castigar. Madrid, Siglo XXI. 2010.

FURTADO, V. El lenguaje inclusivo como política lingüística de género, en Revista digital de políticas lingüísticas. Vol 5, pp. 48-70. 2013.

GALLEGO AYALA, J. Eva devuelve la costilla. Nuevo estado de conciencia de las mujeres. Barcelona, Icaria. 2010.

GARCÍA MESEGUER, A. ¿̨Es sexista la lengua española? Una investigación sobre el género gramatical. Barcelona, Paidós. 1994.

GINER, L. La ballena y el reactor. Barcelona, Gedisa. 1987.

GODDARD, A; PATTERSON, L.M. Lenguaje y Género. Cuenca, Ediciones de la Universidad de Castilla-La Mancha. 2005.

GUTIÉRREZ-ZORZNA, M; NOTARIO PACHECO, B; MARTÍNEZ-VIZCAÍNO, $\mathrm{V}$ (coord.). Violencia doméstica contra las mujeres en la prensa escrita. Cuenca, Ediciones Universidad de Castilla-La Mancha. 2009. 
LASH, S. Crítica de la Información. Buenos Aires, Amorrurtu. 2005.

LERNER, G. La creación del patriarcado. Barcelona, Crítica. 1990.

LLORENTE ACOSTA, M. Tú haz la comida que yo cuelgo los cuadros. Madrid, Crítica. 2014.

MARTÍNEZ BENLLOCH, I; BONILLA CAMPOS, A. Sistema sexo/género, identidades y construcción de la subjetividad. Valencia, Universidad de Valencia. 2000.

MARTÍNEZ GARCÍA, J. A. El lenguaje de género y el género lingüístico. Oviedo, Universidad de Oviedo. 2008.

MARTÍNEZ PÉREZ, A. El vuelo de la alondra: violencia sistémica y familiar. En Sociedad y Utopía, Revista de Ciencias Sociales, n³1, pp. 125-140. 2008.

MILLET, K. Política sexual, Madrid, Catedra. 2010.

MOLINA, E; SAN MIGUEL, N. (coord.). Nuevas líneas de investigación en género y desarrollo. Madrid, Universidad Autónoma de Madrid. 2009.

MORACE, S. Origine donna: dal matrismo al patriarcato. Roma, Prospettiva edizioni.1993.

ONU. Declaración sobre la eliminación de la violencia contra la mujer. Resolución de la Asamblea General, 20-12.1993 (Doc. G.A. Res. 48/104), 1994. Disponible en http://www.unhchr.ch/huridocda/huridoca.nsf/\%28symbol\%29/a.res.48.104.sp?opendocument. [Consultado el 2 de mayo de 2013].

PATEMAN, C. El contrato sexual. Barcelona, Antrophos. 1995.

PENALVA, C. El tratamiento de la violencia en los medios de comunicación. En Alternativas. Cuadernos de trabajo social, $\mathrm{n}^{\circ}$ 10, pp. 395-412. 2002.

PÉREZ FERNÁNDEZ, I. Espacio, identidad y género. Sevilla, Arcibel. 2009.

RIVERA, M. Nombrar el mundo en femenino. Pensamientos de las mujeres y teoría feminista. Barcelona, Icaria. 1994.

RUSSELL HOCHSCHILD, A. (2008). La mercantilización de la vida íntima. Apuntes de la casa y el trabajo. Madrid, Katz.

SANAHUYA, M.E. Cuerpos sexuados, objetos y prehistoria. Madrid, Cátedra. 2002.

SAU, V. Para una teoría del modo de producción patriarcal. Aportaciones para una lógica del feminismo. Barcelona, Lasal. 1986.

SIMÓN, M, E. ¿¿Sabía usted que la mitad de alumnos son ciudadanas?. En

MARTÍNEZ BONAFÉ, J. (Coord.) (2003). Ciudadanía, Poder y Educación. Barcelona, Graó. 2003. 
WALTER, N. Muñecas vivientes, el retorno del sexismo. Barcelona, Turner. 2010.

YOUNG, J. El vértigo de la modernidad tardía. Buenos Aires, DIDOT. 2012. 